\title{
EFFECTIVENESS OF AUTOLOGOUS PLATELET RICH PLASMA (PRP) IN TREATMENT OF CHRONIC AND RECURRENT TENDINOPATHIES
}

\section{Dr Rajeev Kumar Kansay \\ Dr Sandeep Kumar Jindal}

\section{Dr Asshwani Soni}

\section{Dr. Sonam Kansay*}

\author{
MBBS, MS Orthopedics, Assistant Professor, Department of Orthopedics \\ Government Medical College and Hospital Sector 32, Chandigarh.
}

MBBS, MS Orthopedics,Consultant Alchemist Hospital; Sector 21, Panchkula.

MBBS, MS Orthopedics, Assistant Professor; Department of Orthopedics

Government Medical College and Hospital Sector 32, Chandigarh.

MBBS, MD Transfusion Medicine., Drug Safety Physician, PAREXEL International Limited. ${ }^{*}$ Corresponding Author

ABSTRACT Background \& Objective: Chronic and Recurrent Tendinopathies causes variable pain and functional impairment in daily routine activities. They are slow to heal and their treatment poses a great challenge for the treating Clinician. Therefore, this study was initiated to explore the effectiveness of PRP in recurrent tendinopathies. Material And Methods: The study population comprised of patients with chronic or recurrent: Achilles tendinitis (AT), Tennis elbow (TE) or Plantar Fasciitis (PF) and were given autologous platelet rich plasma (PRP) injection locally at point of maximal tenderness. The Visual Analog Scale (VAS) was filled by the concerned clinician at base line (Dayl), at 6 weeks and 6 months after the procedure.

Results: The study included 48 patients with mean age $49.5 \pm 10.98$ years. There were 18 male and 30 females. Mean VAS score of all 48 patients at the time of presentation was $8.8 \pm 0.73$. Mean VAS score when calculated separately for AT, TE and PF were $8.3 \pm 0.48,9.4 \pm 0.5$ and $9.5 \pm 0.54$ respectively. Mean VAS score decreased at 6 weeks and at 6 months to $1.8 \pm 2.2$ and $0.72 \pm$ 1.88 respectively for all 48 patients. This decrease in VAS score at 6 weeks and at 6 months was significant when compared for all 48 patients. When compared separately, decrease in VAS at 6 weeks and 6 months was significant for AT and TE group. Conclusions: Local injection of autologous PRP proved to be a promising form of therapy for TE and AT. It is safe and extremely effective in relieving pain and improving function in chronic and recurrent tendinopathies.

KEYWORDS : Visual Analogue Scale, Achilles Tendonitis, Tendinopathy, Autologous Platelet Rich Plasma

\section{INTRODUCTION}

Platelet Rich Plasma therapies represent a major breakthrough in the treatment of many medical conditions and are currently one of the hottest topics in regenerative medicine because of their extraordinary beneficial effects in various ailments. ${ }^{[1]}$ The easy preparation protocols, minimally invasive technique, high efficacy, biosafety and versatility of autologous platelet rich plasma (PRP) preparations have augmented research and its use in both the scientific and medical communities. Although platelets play major role in hemostasis but they also play a reparative role. Beside other organelles, platelets carry storage granules - known as dense and alpha granules - that spill their contents on activation. The dense granules contain adenosine triphosphate, adenosine diphosphate, serotonin, and calcium; that are chiefly responsible for the coagulation cascade. The alpha granules contain various contents including clotting proteins, multiple growth factors and cytokines that in response to platelet activation play a vital role in initiating and supporting the 3 stages of healing -inflammation, proliferation, and remodeling. The known growth factors present in PRP are Platelet-derived growth factor, Vascular endothelial growth factor, Transforming growth factor, Fibroblast growth factor, Epidermal growth factor, Hepatocyte growth factor and Insulin-like growth factor 1. These growth factors have diverse functions but cumulatively they have potential to accelerate tissue and wound healing. ${ }^{[2]}$ Process of healing undergoes through various phases. Beginning with the early inflammatory response- new tissue formation occurs in 2-10 days after injury and is characterized by cellular proliferation and the migration of different cell types; followed by angiogenesis; and later the sprouts of capillaries along with fibroblasts and macrophages replaces the fibrin matrix with granulation tissue that forms the new substrate for cell migration and thus, synthesizes the extracellular matrix. Finally, the tissue enters into the last phase of healing, a long remodeling phase in which granulation tissue matures into a scar. ${ }^{[1]}$

The ideology behind PRP treatment is the reversal of the red blood cell to platelet ratio by decreasing the red blood cells to $5 \%$ (which are less effective in healing) and concentrating the platelets which contains various growth factors to $95 \% .{ }^{[3]}$ These growth factors have a positive influence in clinical situations that require rapid healing and tissue regeneration. Although the average concentration of platelets in whole blood is $200,000 /$ L, PRP preparations contain platelets 2 to 8 times above the baseline values, depending on certain patient variables and the PRP preparation system used. ${ }^{[4,5]}$ Platelet concentrations of less than $1,00,000 / \mu$ l were not reliable for enhancing wound healing and most studies have suggested that tissue reparative efficacy with PRP can be expected with a minimum increase of five times the normal concentration of platelets (approximately 1 million platelets/ l) whereas much higher concentrations did not show further enhancement of wound healing. ${ }^{[6,7]}$

Autologous PRP injections were reportedly first used in 1987 in an open-heart surgery by Ferrari et.al. ${ }^{[8]}$ Currently, PRP injections are being used in various applications, including orthopedics, sports medicine, cardiovascular surgery, ophthalmology, peripheral nerve repair, ulcer care, plastic / cosmetics, facio-maxillary surgery and urology. ${ }^{[1]}$ In Orthopedics, PRP has been used for Bone repair, Joint repair, Osteoarthritis, Muscle injuries, Anterior cruciate ligament reconstruction, Achilles Tendonitis, Rotator Cuff Tendonitis, Tennis Elbow, Patellar Tendonitis Plantar Fasciitis, Lateral Epicondylitis - Tennis Elbow, Medial Epicondylitis - Golfer's Elbow, Degenerative Disc Disease, Peri-operatively with bones grafts and Soft tissue injuries such as meniscal, ligament and muscle tears.

Tendinopathy causes pain and functional impairment in daily 
routine activities. Its treatment includes conservative therapy and surgical interventions. Although effectiveness of oral nonsteroidal anti-inflammatory agents (NSAIDs), topical and injectable medications including corticosteroids and botulinum toxins, splinting, physical therapy, and iontophoresis have been evaluated in many studies but these therapies do not alter the tendon's inherent poor healing properties secondary to poor vascularization. ${ }^{[9]}$ Since, tendinosis is not an inflammatory condition, the rationale for using corticosteroid needs reassessment, particularly as corticosteroids inhibit collagen synthesis, its use usually leads to treatment failure and sometimes even tendon rupture. ${ }^{[1,11]}$ Surgical treatments such as "tenotomy" are also associated with risks of scarring and bleeding, therefore, infrequently used. $^{[12]}$ Keeping in view all these factors, this study was initiated to explore the effectiveness of PRP in recurrent tendinopathies.

\section{MATERIALS \& METHODS}

This Cohort study was carried out in the Department of Orthopedics and Department of Transfusion Medicine in two tertiary care hospitals from June 2015 to May 2017.

The study population comprised of 48 patients with 27 patients of Achilles Tendinopathy (AT), 15 of Tennis Elbow (TE) and 6 patients with Plantar Fasciitis (PF). The Visual Analog Scale (VAS) was filled by the concerned clinicians at base line (Dayl), at 6 weeks and 6 months after the procedure.

\section{Clinical Āssessment}

\section{Inclusion Criteria}

Criteria for inclusion in the study were patients diagnosed as having recurrent tendinopathy of both genders, aged above 18 years (for TE: having pain and tenderness over the lateral aspect of the elbow, which was related to activity level, with a positive wrist extension test, for AT and PF: having inferior heel pain that was usually worse with their first steps in the morning or after a period of inactivity, with maximal tenderness over the anteromedial aspect of the inferior heel) with duration of symptoms more than 3 months and pain severity with minimum score of 5 (based on 10 scale VAS) and when other conservative treatments had failed.

\section{Exclusion Criteria}

Patients were excluded if they were pregnant, older than 75 years, any platelet dysfunction syndrome or any other coagulopathies, local infection at the site of the procedure, recent febrile or infectious disease, use of NSAIDs within 1 week before procedure, use of corticosteroids during last 2 weeks, history of local injection of any medications (steroid, whole blood, or dry needling) within 1 month, hemoglobin $<10 \mathrm{gm} / \mathrm{dl}$, platelet count $<100000 / \mathrm{mm}^{3}$, history of any malignancy , systemic illnesses like significant cardiovascular, renal or hepatic disease, rheumatoid arthritis, any local bony malformations or articular lesions (diagnosed by radiographic imaging), history of recurrent vasovagal syncope, hemodynamic instability or septicemia. Patient unwilling to accept the risks were also excluded from the study.

In AT or PF group of patients further exclusion criteria were; previous surgery for the same, vascular insufficiency or neuropathy related to heel pain and in TE; carpal tunnel syndrome, cervical radiculopathy or peripheral radial nerve injury were excluded.

All included patients on the lst visit were evaluated by a full medical history and physical examination then marked the level of pain on the Visual Analog Scale (VAS) (0-10) and Verbal Pain Intensity Scale (VPIS). VAS recorded the patient's reported pain using a scale of 0-10 as in Numerical Rating scale (NRS) for pain, where 0 was pain-free and 10 was the worst pain imaginable. The score was marked at the point on the line that corresponds with the patient's response. The validity and reliability of self-rating scales like the VAS and NRS had previously been well described. ${ }^{[13,14,15]}$ The VAS and VPIS were reevaluated at 6 weeks and 6 months after the PRP procedure.

\section{Radiographic Āssessment}

All affected patients were screened with standard X-ray projections. Ultrasound or MRI was done for patients with doubtful clinical findings to assess the severity of the disease and to assess the response to PRP therapy. The aim was to exclude calcific tendinitis or other pathology in case of TE and to exclude bony abnormalities of the calcaneus in case of PF.

\section{Preparation of PRP}

Double blood bag (Terumo Penpol Limited) containing $49 \mathrm{ml}$ citrate phosphate dextrose adenine (CPDA) as an anticoagulant was selected and under all aseptic precautions, $100 \mathrm{ml}$ blood was withdrawn from patients after adjusting anticoagulant volume in the original pack to $14 \mathrm{ml}$ (discarding excess $35 \mathrm{ml}$ anticoagulant). Blood collection was done by trained phlebotomist so that single needle prick was sufficient, free flow of blood was maintained and collection occurred within 5-10 minutes (to prevent activation of platelets during blood collection). Collected blood was centrifuged in Cryofuge (REMI Refrigerated Centrifuge) at ambient temperature, first at $1900 \mathrm{~g}$ (soft spin), supernatant PRP was transferred to $2^{\text {nd }}$ bag and clamped. Then, $2^{\text {nd }}$ hard spin was given at $3500 \mathrm{~g}$, platelets gets settled down and only $10-15 \mathrm{ml}$ of plasma was retained to suspend the platelets and rest of supernatant plasma was transferred to the original bag after removing the clamp. Concentrated platelets present in the $2^{\text {nd }}$ bag were the actual PRP product to be used for the same patient from whom it was collected. This bag was separated from the original one after sealing and then stored at $+22 \pm 2^{0}$ $\mathrm{C}$ with continuous shaking on a horizontal Platelet Agitator cum Incubator (REMI Instruments Ltd. ) until used. A closed system was used throughout the process to avoid contamination. The PRP were injected within an hour of preparation. The platelet count of PRP was done using Sysmex Hematology analyzer before and after the preparation. Accepted PRP contained at least two times increase in platelet concentration.

\section{Statistical Analysis:}

The study population comprised of patients with Achilles Tendinitis, Plantar Fascitis and Tennis Elbow. Quantitative variables were described using mean \pm standard deviation (SD) and categorical data by frequency and percentage. There were 27 patients of Achilles Tendinopathy (AT), 15 of Tennis Elbow (TE) and 6 patients with Plantar Fasciitis (PF). Levene's test for equality of variances and t-test for equality of means were used to examine the changes of VAS at base line and at follow-up after treatment. In all tests, $p$ value $<0.05$ were statistically significant. The study results concluded that a Significant Pain Reduction was achieved at successive Stages of Follow-up.

\section{Ethical Considerations}

The World Anti-Doping Agency (WADA) is an international independent agency that regulates doping free sport by enforcing the Anti-Doping Code. WADA monitors the current literature, conducts comprehensive consultations and, upon agreement by expert panels, releases an annual list of prohibited substances. PRP, after being mentioned in its list of prohibited items (intramuscular PRP injections were prohibited) for the first time in 2010, was subsequently deleted from the 2011 Prohibited List. ${ }^{[16,17]}$

At our institutes, all patients gave informed written consent for inclusion in the study. The process of the treatment was explained to the patients and the written consent form was 
signed or fingerprinted by the patient. The institutional review board of both the institutions approved the protocol of this study.

\section{PRP Injection Procedure}

Under all aseptic precautions, the skin of the injection site was prepared with povidone iodine scrub and spirit and then draped and under ultrasound guidance, $2 \mathrm{ml}-5 \mathrm{ml}$ of autologous PRP was injected under sterile conditions using a $22 \mathrm{G}$ needle at point of maximal tenderness and maximal edema using a peppering technique spreading in a clock-like manner to achieve a more expansive zone of delivery. $2 \mathrm{ml}$ of $\mathrm{l}$ $\%$ lidocaine was injected locally 5 minutes before the injection of PRP in anxious and apprehensive patients. Post procedure ultrasound was done to check the presence of fluid in the desired space. After the procedure all patients were instructed to rest the elbow and wrist (in cases of TE) and to avoid weight bearing (in cases of AT or PF) for 48 hours. Patients were instructed to receive acetaminophen and ice therapy for pain relief while the use of any NSAIDs or steroids was strictly prohibited for 1-month after the procedure. No stressful activity was allowed for 6 -weeks while light exercise was initiated after $10-12$ days as returning to stressful activity before 6-weeks could result in incomplete healing of the treated tissue. Patients were generally re-examined 2-6 weeks after the procedure to follow pain, function and assess the improvement and to discuss the concerns and future course. The patients were allowed to perform full activities of daily living after 4 weeks. The positive effects of the injection usually occur within a week after the injection. Out of 48 patients, 43 patients were considered for the second PRP procedure, within $2-4$ weeks following the first procedure, depending on the basis of functional outcome and patient's willingness.

\section{RESULTS}

The study included 48 patients with mean age $49.5 \pm 10.98$ years. There were 18 male and 30 females. Out of 48 patients 27 patients had AT (Males-11 and Females-16), 15 patients had TE (Males-5 and Females-10) and 6 patients had PF(Males-2 and Females-4).(Table - 1).

\begin{tabular}{|c|c|c|}
\hline \multicolumn{3}{|l|}{ Table - 1} \\
\hline & $\begin{array}{l}\text { Age } \\
\text { (Mean +/- S.D.) }\end{array}$ & Male : Female \\
\hline $\begin{array}{l}\text { All patients } \\
(\mathrm{n}=48)\end{array}$ & $49.5 \pm 10.98$ & $18: 30$ \\
\hline $\begin{array}{l}\text { AT group } \\
(\mathrm{n}=27)\end{array}$ & $53.8 \pm 9.83$ & 11:16 \\
\hline $\begin{array}{l}\text { TE group } \\
(\mathrm{n}=15)\end{array}$ & $44 \pm 11.05$ & $5: 10$ \\
\hline $\begin{array}{l}\text { PF group } \\
(\mathrm{n}=06)\end{array}$ & $43.5 \pm 7.12$ & $2: 4$ \\
\hline
\end{tabular}

Mean VAS score of all 48 patients at the time of presentation was $8.8 \pm 0.73$. Mean VAS score when calculated separately for AT, TE and PF were $8.3 \pm 0.48,9.4 \pm 0.5$ and $9.5 \pm 0.54$ respectively (Table - 2 ).

\section{Table - 2}

\begin{tabular}{|l|l|l|}
\hline \multicolumn{2}{|l}{} & VAS (Mean +/- S.D.) \\
\hline All patients $(\mathrm{n}=48)$ & 0 weeks & $8.8 \pm 0.73$ \\
\cline { 2 - 3 } & 6 weeks & $1.8 \pm 2.2$ \\
\cline { 2 - 3 } & 6 months & $0.72 \pm 1.88$ \\
\hline \multirow{4}{*}{ AT group $(\mathrm{n}=27)$} & 0 weeks & $8.3 \pm 0.48$ \\
\cline { 2 - 3 } & 6 weeks & $1.5 \pm 1.28$ \\
\cline { 2 - 3 } & 6 months & $0.33 \pm 0.67$ \\
\hline \multirow{4}{*}{ TE group $(\mathrm{n}=15)$} & 0 weeks & $9.4 \pm 0.5$ \\
\cline { 2 - 3 } & 6 weeks & $1.2 \pm 2.0$ \\
\cline { 2 - 3 } & 6 months & $0.4 \pm 0.82$ \\
\hline PF group $(\mathrm{n}=06)$ & 0 weeks & $9.5 \pm 0.54$ \\
\cline { 2 - 3 } & 6 weeks & $4.5 \pm 3.98$ \\
\cline { 2 - 3 } & 6 months & $3.3 \pm 4.5$ \\
\hline
\end{tabular}

Mean VAS score decreased at 6 weeks and at 6 months to 1.8 \pm 2.2 and $0.72 \pm 1.88$ respectively for all 48 patients. Mean
VAS score decreased at 6 weeks and 6 months when calculated separately for AT, TE and PF group (Table - 2). This decrease in VAS score at 6 weeks and at 6 months was significant when compared for all 48 patients. When compared separately, decrease in VAS at 6 weeks and 6 months was significant for AT and TE group. For PF group decrease in VAS was significant when compared at 6 weeks, however when compare from 6 weeks to 6 months the decrease was not significant (Table - 3 ).

\begin{tabular}{|c|c|c|c|}
\hline \multicolumn{4}{|l|}{ Table - 3} \\
\hline & & $\begin{array}{l}\text { Difference in VAS } \\
\text { (Mean +/- S.D.) }\end{array}$ & $\begin{array}{l}\text { P value } \\
\text { (paired t } \\
\text { test) }\end{array}$ \\
\hline \multirow[t]{3}{*}{$\begin{array}{l}\text { All patients } \\
(n=48)\end{array}$} & $\begin{array}{l}0 \text { weeks - } 6 \\
\text { weeks }\end{array}$ & $7.0 \pm 2.28$ & 0.000 \\
\hline & $\begin{array}{l}6 \text { weeks - } 6 \\
\text { months }\end{array}$ & $1.08 \pm 1.08$ & 0.000 \\
\hline & $\begin{array}{l}0 \text { weeks - } 6 \\
\text { months }\end{array}$ & $8.08 \pm 1.92$ & 0.000 \\
\hline \multirow[t]{3}{*}{$\begin{array}{l}\text { AT group } \\
(\mathrm{n}=27)\end{array}$} & $\begin{array}{l}0 \text { weeks - } 6 \\
\text { weeks }\end{array}$ & $6.77 \pm 1.42$ & 0.000 \\
\hline & $\begin{array}{l}6 \text { weeks - } 6 \\
\text { months }\end{array}$ & $1.22 \pm 0.93$ & 0.000 \\
\hline & $\begin{array}{l}0 \text { weeks - } 6 \\
\text { months }\end{array}$ & $8.0 \pm 0.67$ & 0.000 \\
\hline \multirow[t]{3}{*}{$\begin{array}{l}\text { TE group } \\
(n=15)\end{array}$} & $\begin{array}{l}0 \text { weeks - } 6 \\
\text { weeks }\end{array}$ & $8.2 \pm 1.78$ & 0.000 \\
\hline & $\begin{array}{l}6 \text { weeks - } 6 \\
\text { months }\end{array}$ & $0.8 \pm 1.2$ & 0.022 \\
\hline & $\begin{array}{l}0 \text { weeks - } 6 \\
\text { months }\end{array}$ & $9.0 \pm 0.65$ & 0.000 \\
\hline \multirow[t]{3}{*}{$\begin{array}{l}\mathrm{PF} \text { group } \\
(\mathrm{n}=06)\end{array}$} & $\begin{array}{l}0 \text { weeks - } 6 \\
\text { weeks }\end{array}$ & $5.0 \pm 4.51$ & 0.042 \\
\hline & $\begin{array}{l}6 \text { weeks - } 6 \\
\text { months }\end{array}$ & $1.16 \pm 1.47$ & 0.110 \\
\hline & $\begin{array}{l}0 \text { weeks - } 6 \\
\text { months }\end{array}$ & $6.16 \pm 4.91$ & 0.028 \\
\hline
\end{tabular}

Complication in patients following the procedure was seen in one female patient only who developed mild vasovagal reaction and two patients of PF showed lack of efficacy (No improvement) following the first PRP procedure and didn't turn up for the $2^{\text {nd }}$ procedure . Vasovagal reaction in that patient was probably due to the pain and anxiety and she underwent $2^{\text {nd }}$ procedure after 2 weeks under local anesthesia without developing any complications.

\section{DISCUSSION}

The tendons are relatively hypovascular proximal to the tendon insertion which predispose them to hypoxic tendon degeneration and thus tendinopathies. ${ }^{[18]}$ Tendinopathy refers to a degenerative condition of tendons marked by the chronic loss of collagen, tissue integrity, stability and strength. Causes are multifactorial, but natural aging, injury, repetitive stress, neural, vascular and hormonal inputs contribute to it. Present study involved patients from rural areas of Punjab and Haryana province of India who are mainly associated with agriculture and farming industries. Therefore, aging, wear and tear, injury, repetitive stress were the main factors associated with tendinopathies in these patients. $62.5 \%$ of our patients were above the age of 50 indicating that natural aging and wear and tear plays a definitive role in occurrence of tendinopathies.

In our study we found that VAS score decreased significantly from the time of PRP administration to 6 weeks which further decreased significantly at 6 months. This shows that treatment is effective till 6 months. To analyze the effect for longer duration another study is required. When analyzed separately for $\mathrm{AT}, \mathrm{TE}$ and $\mathrm{PF}$ groups, this decrease in VAS score was significant from the day of PRP administration to 6 
months. This shows that the treatment is effective for all groups.

Muscle healing is an intricate and dynamic process aimed at restoration of anatomic continuity and function of the injured muscle and it has been found that local delivery of PRP shortens the recovery time after a muscle strain injury in a small-animal model. ${ }^{[19]}$ There is enough laboratory evidence that PRP stimulates processes associated with tendon healing in damaged tendons by growth factors present in it. ${ }^{[3,20]}$ Mishra and Pavelko prospectively evaluated cases of medial and lateral epicondylitis after injection of buffy coat PRP and noted greater clinical improvement by 8 weeks post injection, with continued improvement at just over 2 years. ${ }^{[5]}$ Not only plateletrich plasma, but also platelet-poor plasma, stimulates cell proliferation and total collagen production. ${ }^{[20]}$ Increased production of endogenous growth factors have been found in human tendons treated with PRP. ${ }^{[2]}$ These mechanisms explain why PRP alone or whole blood application can have a lasting effect on the healing process.

In a systematic review and network meta-analysis of randomized controlled trials by Krogh in 2013, the comparative effectiveness and safety of injection therapies in patients with lateral epicondylitis were assessed and it was observed that both autologous blood and platelet-rich plasma were statistically superior to placebo in clinical trials. ${ }^{[22]}$ Local Steroid injection is a popular method of treating these conditions but only seem to be useful in the short term and only to a small degree. ${ }^{[23]}$ It was also demonstrated that a single injection of PRP is both safe and effective, improves pain and function more effectively than corticosteroid injection and these improvements were sustained over time with no reported complications. ${ }^{[24,25,26]}$ Regarding pain reduction, PRP treatment seems to be an effective treatment for chronic lateral elbow epicondylitis and superior to autologous blood in short term. ${ }^{[27,28]}$ While Raeissadat et.al in their consecutive study, concluded that PRP and autologous whole blood injections are both effective methods to treat chronic lateral epicondylitis and their efficacy persisted during long term follow up. ${ }^{[2]}$

There are no standardized criteria that define PRP. Different techniques yield wide variability in terms of platelet count and concentration making it difficult to compare clinical trials that use PRP or draw conclusions concerning its clinical efficacy in orthopedic procedures. ${ }^{[30]}$ A clear consensus over the best orthobiologic substance, their method of preparation and usage of these substances is lacking. Much of the confusion is due to the fact that studies ranging from randomized controlled trials to case reports present variable results, and the interpretations are wide-ranging. ${ }^{[31]}$

The limitations of our study were relatively small sample size, absence of a control group receiving no intervention or absence of a comparator group receiving other treatments, and lack of long-term follow-up evaluations to exclude recurrence.

\section{CONCLUSION}

Local injection of autologous PRP proved to be a promising form of therapy for TE and AT. It is safe and extremely effective in relieving pain and improving function in chronic and recurrent tendinopathies.

\section{Conflict Of Interest}

All the authors responsible for this work declare no conflict of interest.

\section{REFERENCES}

1. Sánchez, Andia I, Anitua E, Sánchez P. Platelet Rich Plasma (PRP) Biotechnology: Concepts and Therapeutic Applications in Orthopedics and Sports Medicine. In: Dr. Eddy C. Agbo, editor. Innovations in Biotechnology. In Tech 2012. p.113-138
(SBN:978-953-51-0096-6,InT ech,Availablefrom: http://www.intechopen.com/ books/innovations-in-biotechnology/platelet-rich-plasma-prp-bio technology concepts- and-therapeutic applications-in-orthopedics-andsports medicine

2. Anitua E, Sanchez M, Nurden AT, Nurden P, Orive G, Andia I. New insights into and novel applications for platelet-rich fi brin therapies. Trends Biotechnol 2006, 24:227

3. Dhillon RS, Schwarz EM, Maloney MD. Platelet-rich plasma therapy - future or trend? Arthritis Research \& Therapy 2012; 14:219 http://arthritisresearch.com/content/14/4/219

4. Platelet-Rich Plasma Update: Clinical Use in Musculoskeletal Care. April 30, 2012 / Osteoarthritis, Arthritis. By Christopher Allan Webb, PA-C

5. Mishra A, Pavelko T. Treatment of chronic elbow tendinosis with buffered platelet-rich plasma. Am J Sports Med. 2006;34:1774-1778.

6. Marx RE. Platelet-rich plasma (PRP): what is PRP and what is not PRP? Implant Dent 2001; 10:225-228

7. Marx RE. Platelet-rich plasma: evidence to support its use. J Oral Maxillofac Surg 2004; 62:489-496.

8. Ferrari M, Zia S, Valbonesi M, Henriquet F, Venere G, Spagnolo S et.al. A new technique for hemodilution, preparation of autologous platelet-rich plasma and intraoperative blood salvage in cardiac surgery. Int J Artif Organs 1987; 10:47-50.

9. Kazemi M, Azma K, Tavana B, Moghaddam FR, Panahi A. Autologous blood versus corticosteroid local injection in the short-term treatment of lateral elbow tendinopathy: a randomized clinical trial of efficacy. American Journal of Physical Medicine and Rehabilitation 2010; 89: 660-667, 2010. View at Publisher · View at Google Scholar · View at Scopus

10. Anastassiades T, Dziewiatkowski D: The effect of cortisone on connective tissue in the rat. J Lab Clin Med 1970; 75: 826- 839.

11. Kapetanos G: The effect of local corticosteroids on the healing and biomechanical properties of the partially injured tendon. Clin Orthop 1982; 163:170-179

12. Sharma P, Maffulli N. Tendon Injury and Tendinopathy. Healing and Repair. J. Bone Joint Surg. Am. 2005; 87:187- 202.

13. Turchin DC, Beaton DE, Richards RR. Validity of observer-based aggregate scoring systems as descriptors of elbow pain, function, and disability. Journal of Bone and Joint Surgery American 1998; 80: 154-162, 1998. View at Google Scholar View at Scopus

14. Boonstra AM, Schiphorst Preuper HR, Reneman MF, Posthumus JB, Stewart RE: Reliability and validity of the visual analogue scale for disability in patients with chronic musculoskeletal pain. Int J Rehabil Res Dev 2008; 31:165-169.

15. Hjermstad MJ, Fayers PM, Haugen DF, Caraceni A, Hanks GW, Loge JH et al Studies Comparing Numerical Rating Scales, Verbal Rating Scales, and Visual Analogue Scales for Assessment of Pain Intensity in Adults: A Systematic Literature Review. Journal of Pain and Symptom Management 2011;41:1073-1093

16. World Anti-Doping Agency: The World Anti-Doping Code. The 2010 Prohibited List. International Standard [http://www.wada-ama.org/ Documents/ World Anti-Doping Program/WADP-Prohibited-list/WADA Prohibited List 2010_EN.pdf]

17. World Anti-Doping Agency: The World Anti-Doping Code. The 2010 Prohibited List. International Standard [http://www.wada-ama.org/ Documents/World Anti-Doping Program/WADP-Prohibited list/To_be_effective/ WADA_Pro hibited List 2011 EN.pdf]

18. Altan L, Kanat E. Conservative treatment of lateral epicondylitis: comparison of two different orthotic devices. Clin Rheumatol 2008;27:1015-9.

19. Hammond JW, Hinton RY, Curl LA, Muriel J M, Lovering RM. Use of autologous platelet-rich plasma to treat muscle strain injuries. Am J Sports Med 2009, 37:1135-1142.

20. Monto RR: Platelet rich plasma treatment for chronic Achilles tendinosis. Foot Ankle Int 2012; 33:379-385. PubMed Abstract

21. Kaux JF, Crielaard JM. Platelet-rich plasma application in the management of chronic tendinopathies. Acta Orthopaedica Belgica 2013; 79:10-15 View a Google Scholar

22. Krogh TP, Bartels EM, Ellingsen T, Stengaard PK, Buchbinder R, Fredberg U, et al. Comparative effectiveness of injection therapies in lateral epicondylitis: $a$ systematic review and network meta-analysis of randomized controlled trials. Am J Sports Med 2013; 41:1435-1446. PubMed Abstract | Publisher Full Text

23. Crawford F, Thomson C. Interventions for treating plantar heel pain (Review). Cochrane Database Syst Rev. 2003;(3):CD000416.

24. Peerbooms JC, Sluimer J, Bruijn DJ, Gosens T. Positive effect of an autologous platelet concentrate in lateral epicondylitis in a double-blind randomized controlled trial: platelet-rich plasma versus corticosteroid injection with a 1 year follow-up. Am J Sports Med. 2010;38:255-62

25. Omar AS, Ibrahim ME, Ahmed AS, Said M. Local injection of autologous platelet rich plasma and corticosteroid in treatment of lateral epicondylitis and plantar fasciitis: Randomized clinical trial. The Egyptian Rheumatologist $2012 ; 34,43-49$

26. Hechtman KS, Uribe JW, Botto-vanDemden A, Kiebzak GM. Platelet-rich plasma injection reduces pain in patients with recalcitrant epicondylitis. Orthopedics 2011, 34:92.Thanasas C

27. Papadimitriou G, Charalambidis C, Paraskevopoulos I, Papanikolaou A. Platelet-rich plasma versus autologous whole blood for the treatment of chronic lateral elbow epicondylitis: a randomized controlled clinical trial. Am J Sports Med. 2011 Oct;39(10):2130-4. doi: 10.1177/0363546511417113. Epub 2011 Aug 2. Raeissad at

28. SA, Sedighipour L, Rayegani SM, Bahrami MH, Bayat M, Rahimi REffect of Platelet-Rich Plasma (PRP) versus Autologous Whole Blood on Pain and Function Improvement in Tennis Elbow: A Randomized Clinical Trial. Pain Research and Treatment 2014; Article ID 191525: 8 pages http://dx.doi.org/10.1155/2014/191525

29. Raeissadat SA, Rayegani SM, Hassanabadi H, Rahimi R, Sedighipour L Rostami K. Is Platelet-rich plasma superior to whole blood in the management of chronic tennis elbow: one year randomized clinical trial. BMC Sports Science, Medicine and Rehabilitation 2014, 6:12 doi:10.1186/2052-1847-6-12 
30. Cohn CS, Lockhart E, McCullough JJ. The use of autologous platelet-rich plasma in the orthopedic setting. Transfusion 2015. doi: 10.1111/trf.13005. [Epub ahead of print]

31. Dhillon MS, Behera P, Patel S, Shetty V. Orthobiologics and platelet rich plasma. Indian J Orthop. 2014; 48: 1-9. doi: 10.4103/0019-5413.125477 PMCID: PMC3931137 